eells, is correspondingly more diffieult. The second part of the book is concerned with such problems, and it contains a lot of useful data for design as well as practical experience in dealing with highly active materials up to the $1,000 \mathrm{MeV}$. curie level. It refers particularly to work with fission products and irradiated metallurgical specimens. This part is necessarily rather less satisfactory than the first, because these techniques are at present developing more rapidly than those for handling alpha emitters.

The book is well produced, and one appreciates the heavy task of the editors and publishers in attaining this result. Nevertheless, there is much to be said in favour of adopting a simpler, cheaper and quicker form of publication for the proceedings of symposia such as this one.

\section{MATRIX ALGEBRA IN STRUCTURAL ANALYSIS}

Linear Structural Analysis

An Introduction to the Influence Coefficient Method applied to Statically Indeterminate Structures. By Prof. P. B. Morice. Pp. xii +170 . (Liondon: Thames and Hudson, Ltd., 1959.) 35s. net.

(

$\mathrm{NE}$ of the most important advances in the theory of elastic structures during the past few years has been the development of matrix methods of analysis. This work has been considerably stimulated by the advent of automatic digital computers, since these machines are very well suited to the manipulation of large matrices.

Methods of structural analysis may be divided into two groups. 'The first, often termed 'equilibrium' or 'stiffness' methods, consider joint displacements as the basic unknowns, and proceed by setting up and solving the equations of joint equilibrium. The second group, known as 'compatibility' or 'flexibility' methods, attack the problem in terms of the redundant forces and moments in a structure, determining these by equations of displacement compatibility.

Prof. P. B. Morice's book is entirely devoted to the second of these two approaches. He commences by discussing general energy theorems, influence coefficients and indeterminacy. The treatment of the latter subject follows recent work by Henderson and is extremely thorough. The central section of the book presents a short account of matrix algebra and the associated numerical techniques, described from the point of view of a human computer using a desk calculating machine. After this the flexibility coefficient method of analysis is presented in matrix notation, with examples of its use in particular cases. The book concludes with a brief account of the way in which matrix work can be carried out on a Pegasus computer.

The development of matrix methods of structural analysis is by no means complete, and the theoretician will doubtless find that many of the ideas presented in this book are capable of further generalization and extension. Although the conciseness and generality of matrix notation are well displayed, there are several places where unusual symbols (such as $\mathrm{x}$ and $\mathrm{n}$ for force vectors) make the text more difficult than it might have boen for a newcomer to the subject. There are also a fow misprints which suggest rather hurried proof reading.
From the short title on the cover, and various paragraphs in the preface and introduction, the reader with a limited knowledge of structural analysis might well assume that the best, if not the only, way of using matrices in structural analysis was by means of the flexibility methods deseribed in this book. The book would have been a very much more valuable one if it had contained a parallel account of the equally important stiffness methods of analysis, with demonstrations of the relative merits of the two approaches in a number of examples.

R. K. LIVESLEY

\section{THE GEOLOGICAL DEVELOPMENT OF NORTH AMERICA}

The Evolution of North America

By Dr. Philip B. King. Pp. xvii +190 . (Princeton, N.J. : Princeton University Press ; London : Oxford University Press, 1959.) 60s. net.

7 HE publication of a book which collates and interprets the considerable number of available facts concerning the regional geology of North America can be expected to be a notable event when the author has the background of Dr. P. B. King, with wide and long experience in the United States Geological Survey and interests covering tectonics, stratigraphy and physical geology. The story of the growth of the northern part of the American continent is not treated chronologically but regionally, with emphasis on selected areas of the United States. Although the book arises from lectures to graduates, the author explains that it is not a text-book in the usual sense; prominence is given, however, to 'Reference Material', a list of maps and books, which receives precedence over 'Contents' and is supplemented by 'References' (which are not referred to in the body of the text) at the end of each chapter.

After an introductory chapter addressed mainly to the layman, the Canadian Shield is treated in broad outline. When he turns to consider the Interior Lowlands, Dr. King is able to draw on his personal experience of field work in the West Texas Basin, and in the chapter on the Appalachians his close acquaintance with the complexities is evident. Valuable comments on geosynclines and the growth of the Appalachians, stemming from earlier publications by the author, are followed by examination of modern analogues of geosynclines around the Gulf of Mexico and the Caribbean. The second half of the book examines the mountain chains and intermontane regions in the west, largely in the United States. The complex subdivisions of this belt are elearly outlined and interesting notes and anecdotes concerning its exploration are included.

The geological maps and sections are admirably executed, and the sketches by Trudy King above chapter headings add a pleasing touch. The typography can only be criticized in details ; sub-headings tend to become obscured in the text and the list of contents (pp. xi-xiv) suffers from lack of variation in fount and insufficient indentation of sub-headings.

Dr. King succeeds, with a fresh and stimulating approach, in outlining a great deal of the structural framework of North America but is only partially suecessful in fulfilling the promise implied by his title with respect to historical geology.

$$
\text { J. W. CowIE }
$$

